\title{
Does Tumor Extent on Needle Prostatic Biopsies Influence the Value of Perineural Invasion to Predict Pathologic Stage $>$ T2 in Radical Prostatectomies?
}

\author{
Athanase Billis, Maisa M. de Quintal, Luciana Meirelles, Leandro L. L. Freitas, Luis A. Magna, \\ Ubirajara Ferreira
}

Department of Anatomic Pathology (AB, MMQ, LM, LLLF), Department of Medical Genetics/ Biostatistics (LAM), and Department of Urology (UF), School of Medicine, University of Campinas (Unicamp), Campinas, SP, Brazil

\begin{abstract}
Purpose: Perineural invasion (PNI) on needle prostatic biopsies (NPB) has been controversial as a marker of extraprostatic extension and consequently for planning of nerve-sparing radical prostatectomy (RP). The aim of this study was to find whether tumor extent on NPB influences the value of PNI to predict stage $>$ pT2 on RP.

Materials and Methods: This retrospective study was based on 264 consecutive patients submitted to radical retropubic prostatectomy. Their NPB were matched with whole-mount processed and totally embedded surgical specimens. Tumor extent on NPB was evaluated as the percentage of linear tissue in mm containing carcinoma in all cores. Considering the median value, patients were stratified into 2 groups: harboring less or more extensive tumors on NPB. Univariate and multivariate logistic regression analyses were used to relate stage $>$ pT2 to PNI and other clinical and pathological variables. Results: In patients with more extensive tumors, PNI was predictive of stage $>$ pT2 in univariate analysis but not in multivariate analysis. In less extensive tumors, PNI showed no association between any clinical or pathological variables studied; no difference in the time to biochemical progression-free status compared to patients without PNI; and, no predictive value for pathological stage $>$ pT2 on both univariate and multivariate analyses.

Conclusion: Tumor extent on NPB influences the predictive value of PNI for pathologic stage $>$ pT2 on RP. With a higher number of small tumors currently detected, there is no evidence that perineural invasion should influence the decision on preservation of the nerve during radical prostatectomy.
\end{abstract}

Key words: prostate; prostatic neoplasms; biopsy; needle; prostatectomy; prognosis Int Braz J Urol. 2010; 36: 439-49

\section{INTRODUCTION}

Perineural invasion (PNI) on needle prostatic biopsies as a marker of extraprostatic extension has been controversial (1-15). In almost all studies, perineural invasion has been related to extraprostatic extension in univariate analysis but in only a few studies in multivariate analysis. The practical importance relates to the decision of whether to sacrifice part or all of the neurovascular bundle on the side of the biopsy with PNI when planning nerve-sparing radical prostatectomy. The aim of this study was to determine whether tumor extent on needle biopsies significantly influences the value of PNI to predict 
stage $>$ pT2 (pT3a and/or pT3b) on radical prostatectomies.

\section{MATERIALS AND METHODS}

This retrospective study was based on 264 consecutive patients submitted to radical retropubic prostatectomy by one surgeon (UF) in the period 1997 to 2008 due to clinically localized (T1c or T2) prostate adenocarcinoma. Their needle prostatic biopsies (mean 9 cores per biopsy) were matched with whole-mount processed and totally embedded surgical specimens. A mean of 32 paraffin blocks were processed, and $6 \mu \mathrm{m}$ sections from each block were stained with hematoxylin and eosin. PNI was considered as prostate cancer extension along the perineural sheath (Figure-1). The presence of any PNI, regardless of amount, was recorded as positive for PNI. Positive surgical margins were defined as cancer cells touching the inked surface of the prostate. Extraprostatic extension (pT3a) was diagnosed whenever cancer was seen in adipose tissue and, in case of desmoplastic response, whenever a protuberance corresponding to extension of tumor into the periprostatic tissue was seen (16). Seminal vesicle invasion (pT3b) was defined as invasion of the muscular wall (17).

Extent on needle biopsy was evaluated as the percentage of linear tissue in $\mathrm{mm}$ containing carcinoma. Considering the median value of extent, biopsies were stratified into 2 equal groups: 132 biopsies with less extensive and 132 biopsies with more extensive tumors. Tumor extent on radical prostatectomy was estimated by use of a point-count method previously described $(18,19)$. Grading was according to the standard Gleason system $(20,21)$. All pathological findings were evaluated by one senior uropathologist $(\mathrm{AB})$.

Clinical variables analyzed included preoperative serum prostate-specific antigen (PSA), age and clinical stage (T1c or T2). Total serum PSA was measured utilizing previous validated Immulite ${ }^{\circledR}$ PSA kit. Biochemical progression was defined as PSA $\geq 0.2$ $\mathrm{ng} / \mathrm{mL}$ according to recommendation of the American Urological Association (22). After radical prostatectomy, serum PSA was drawn every 3 months during the first year, every 6 months during the second year, and annually thereafter. The mean and median follow-

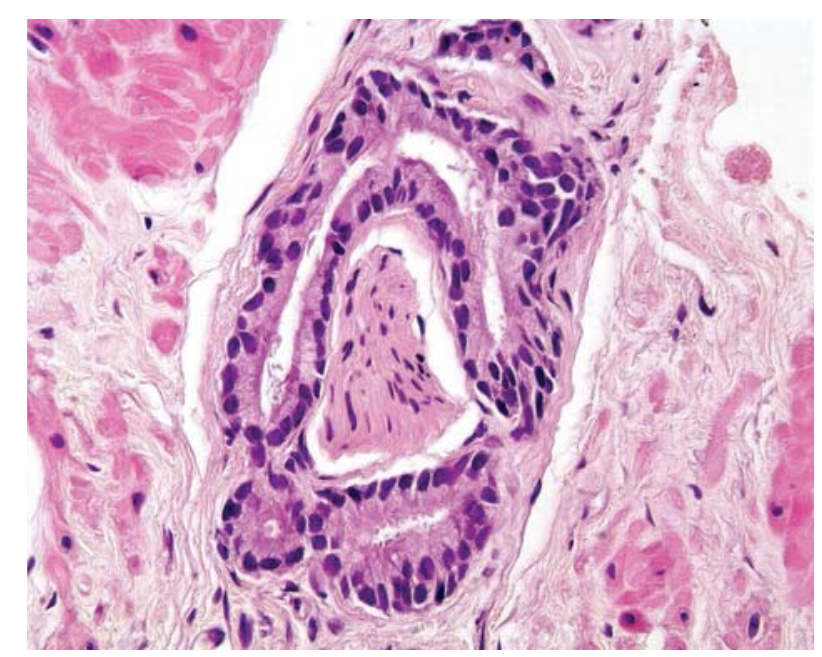

Figure 1 - Perineural invasion on needle prostatic biopsy (HE, X400).

up of the patients was 28 and 20 months, respectively. No patient of this series was treated before or after surgery.

The data were analyzed using the MannWhitney test for comparison of means and the Fishers exact test for comparison of proportions. Time to biochemical (PSA) progression-free outcome was studied using the Kaplan-Meier product-limit analysis; the comparison between the groups was done using the Log-rank test. Univariate and multivariate analyses using a logistic regression model was used to relate the outcomes of prostatectomy stage $>$ pT2 to several clinical and pathological variables. Two-sided $\mathrm{P}$ value $<0.05$ was considered statistically significant. All statistical analyses were performed using the commercially available SPSS 15.0.

\section{RESULTS}

Table- 1 shows the clinical and pathological findings of the 264 patients studied. Perineural invasion was present in 48/264 (18.2\%) biopsies. The median value of tumor extent on biopsy was $13.6 \%$. The frequency of PNI in the group with less extent tumors ( $\leq 13.6 \%$ of tissue in mm containing carcinoma) was $10.6 \%$; in the group with more extensive tumors ( $>13.6 \%$ of tissue in $\mathrm{mm}$ containing carcinoma) the frequency of PNI was $25.8 \%$. 
Table 1 - Clinical and pathological characteristics of the study population.

\begin{tabular}{|c|c|}
\hline Variable & $\mathbf{N}(\%)$ \\
\hline \multicolumn{2}{|l|}{ Age (years) } \\
\hline Mean \pm SD & $63.2 \pm 6.6$ \\
\hline Median & 64 \\
\hline Range & $43-76$ \\
\hline \multicolumn{2}{|l|}{ Clinical stage } \\
\hline T1c & $111(44)$ \\
\hline $\mathrm{T} 2$ & $141(56)$ \\
\hline \multicolumn{2}{|c|}{ Preoperative PSA (ng/mL) } \\
\hline Mean \pm SD & $9.2 \pm 5.4$ \\
\hline Median & 7.8 \\
\hline Range & $0.6-35$ \\
\hline \multicolumn{2}{|c|}{ Gleason score (needle biopsy) } \\
\hline Mean \pm SD & $6.4 \pm 0.6$ \\
\hline Median & 6 \\
\hline Range & $4-9$ \\
\hline \multicolumn{2}{|c|}{ Tumor extent in biopsy (\%) } \\
\hline Mean \pm SD & $19.7 \pm 19.1$ \\
\hline Median & 13.6 \\
\hline Range & $0.4-100$ \\
\hline \multicolumn{2}{|c|}{$\begin{array}{l}\text { Tumor extent in radical prostatectomy } \\
\text { (positive points) }\end{array}$} \\
\hline Mean \pm SD & $36.7 \pm 36.4$ \\
\hline Median & 27 \\
\hline Range & $1-225$ \\
\hline \multicolumn{2}{|l|}{ Positive margins } \\
\hline Absent & $146(55.3)$ \\
\hline Present & $118(44.7)$ \\
\hline \multicolumn{2}{|c|}{ Extraprostatic extension (pT3a) } \\
\hline Absent & $194(73.8)$ \\
\hline Present & $69(26.2)$ \\
\hline \multicolumn{2}{|c|}{ Seminal vesicle invasion (pT3b) } \\
\hline Absent & $230(87.1)$ \\
\hline Present & $34(12.9)$ \\
\hline \multicolumn{2}{|c|}{ Pathologic stage $>$ pT2 (pT3a/pT3b) } \\
\hline Absent & $190(72)$ \\
\hline Present & $74(28)$ \\
\hline
\end{tabular}

$S D=$ standard deviation

Table-2 shows the association of PNI to several clinical and pathological variables comparing patients with less extensive and more extensive tumors. On biopsies showing more extensive tumors and PNI, patients showed statistically significant higher Gleason score on biopsy $(\mathrm{p}=0.02)$, more extraprostatic extension $(p=0.02)$, and more seminal vesicle invasion $(\mathrm{p}=0.04)$. On biopsies showing less extensive tumors and PNI, there was no statistical significant association to all variables studied.

Figures- 2 and 3 show the Kaplan-Meier biochemical progression-free survival curve following radical prostatectomy. In patients with less extensive tumors on biopsy (Figure-2), at 5 years, $71 \%$ of the patients without PNI were free of biochemical progression compared to $83 \%$ of the patients with PNI. There was no statistically significant difference between the groups (log-rank, $p=0.24)$. In patients with more extensive tumors on biopsy (Figure-3), at 5 years, $43 \%$ of the patients without PNI were free of biochemical progression compared to $33 \%$ of the patients with PNI. There was no statistically significant difference between the groups (Log-rank, $p=0.26$ ).

Table- 3 shows the univariate and multivariate logistic regression analyses of several clinical and pathological variables predictive of pathological stage $>$ T2 on radical prostatectomy in patients with less extensive tumors on biopsy. PNI was not predictive of stage $>$ pT2 on both analyses. On univariate analysis, only extent of cancer and Gleason score on biopsy were predictive. On multivariate analysis, extent of tumor on biopsy was statistically significant and Gleason score on the level of significance.

Table-4 shows the univariate and multivariate logistic regression analyses of several clinical and pathological variables predictive of pathological stage $>\mathrm{T} 2$ on radical prostatectomy in patients with more extensive tumors on biopsy. PNI was predictive of stage $>$ pT2 only on univariate analysis. Other variables statistically significant on univariate analysis were preoperative PSA, tumor extent on needle biopsy, and Gleason score on biopsy. On multivariate analysis, only extent of tumor on needle biopsy was an independent predictor of stage $>$ pT2 (pT3a and/or pT3b) on radical prostatectomy.

\section{COMMENTS}

Our study showed that extent of tumor influences the value of PNI to predict pathological stage 


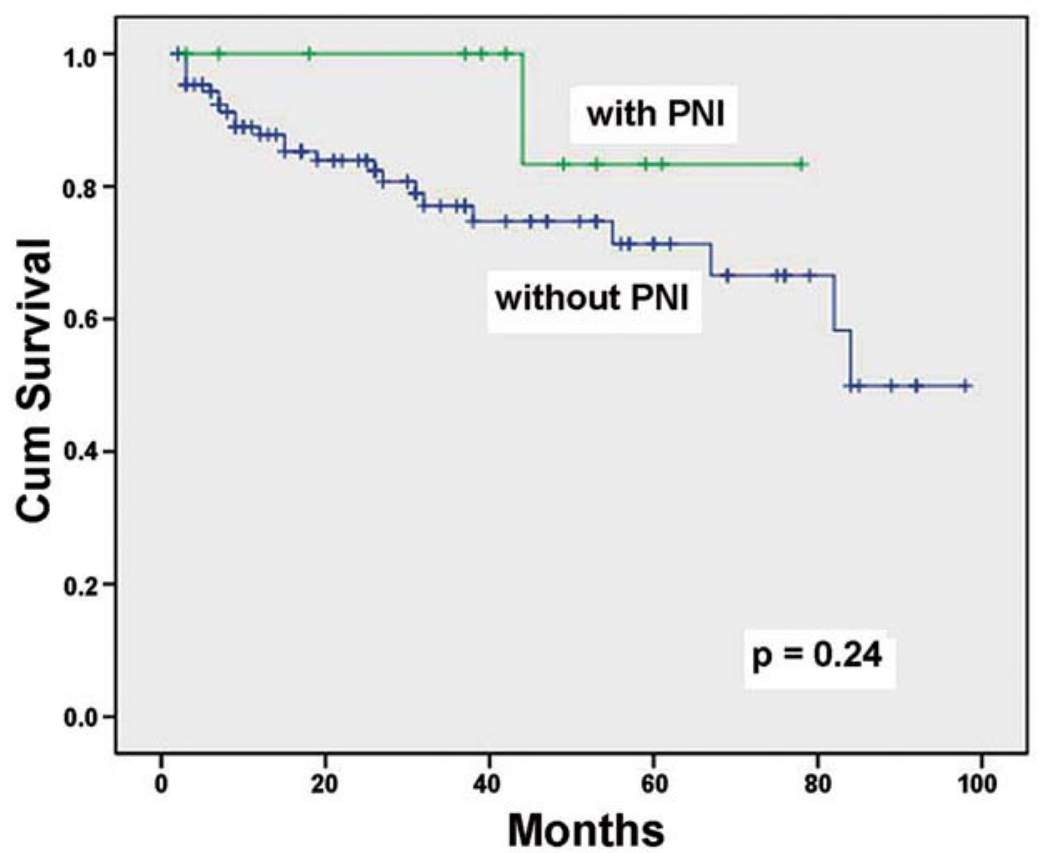

Figure 2 - Kaplan-Meier biochemical (PSA) progression-free survival curve of patients with and without PNI on 132 biopsies with $\leq$ $13.6 \%$ of tissue in mm containing carcinoma (log-rank, $p=0.24)$.

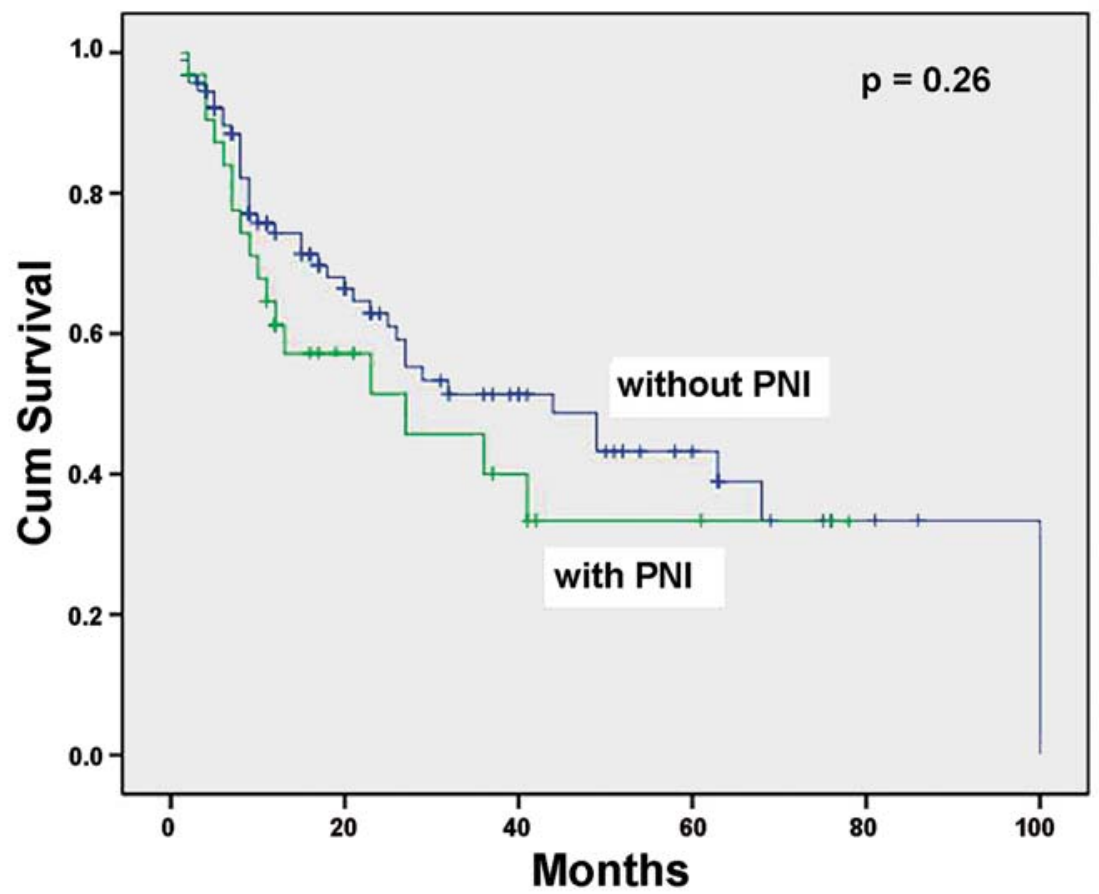

Figure 3 - Kaplan-Meier biochemical (PSA) progression-free survival curve of patients with and without PNI on 132 biopsies with > $13.6 \%$ of tissue in mm containing carcinoma (Log-rank, $p=0.26)$. 
Table 2 - Association of perineural invasion (PNI) to several clinical and pathological variables on 132 biopsies with less extensive tumors $(\leq 13.6 \%$ of tissue in mm containing carcinoma) and 132 biopsies with more extensive tumors $(>13.6 \%$ of tissue in mm containing carcinoma).

\begin{tabular}{lcc}
\hline Variable & $\begin{array}{c}\text { PNI in Biopsies with Less } \\
\text { Extensive Tumors }\end{array}$ & $\begin{array}{c}\text { PNI in Biopsies with More } \\
\text { Extensive Tumors }\end{array}$ \\
\hline Age & p Value & $0.20^{(1)}$ \\
Clinical stage & $0.94^{(1)}$ & $0.66^{(2)}$ \\
Preoperative PSA & $0.47^{(2)}$ & $0.14^{(1)}$ \\
Gleason score on needle biopsy & $0.36^{(1)}$ & $0.02^{(1)}$ \\
Tumor extent on radical prostatectomy & $0.79^{(1)}$ & $0.09^{(1)}$ \\
Positive margins & $0.13^{(1)}$ & $0.16^{(2)}$ \\
Extraprostatic extension & $0.23^{(2)}$ & $0.02^{(2)}$ \\
Seminal vesicle invasion & $0.43^{(2)}$ & $0.04^{(2)}$ \\
\hline
\end{tabular}

(1) Mann-Whitney test; (2) Fisher's exact test

Table 3 - Univariate and multivariate logistic regression analyses of several clinical and pathological variables predictive of pathological stage $>$ pT2 (pT3a/pT3b) on 132 biopsies with less extensive tumors $(\leq 13.6 \%$ of tissue in mm containing carcinoma).

\begin{tabular}{|c|c|c|c|c|}
\hline \multirow[t]{2}{*}{$\begin{array}{c}\text { Clinical and Pathological } \\
\text { Variables }\end{array}$} & \multirow{2}{*}{$\begin{array}{l}\text { Univariate Analysis } \\
\text { Hazard ratio } \\
(95 \% \mathrm{CI})\end{array}$} & \multicolumn{3}{|c|}{$\begin{array}{l}\text { Multivariate } \\
\text { Analysis }\end{array}$} \\
\hline & & p Value & $\begin{array}{l}\text { Hazard ratio } \\
(95 \% \mathrm{CI})\end{array}$ & p Value \\
\hline Age & $1.02(0.95-1.10)$ & 0.63 & $1.01(0.93-1.09)$ & 0.86 \\
\hline Clinical stage & $0.59(0.22-1.60)$ & 0.30 & $0.51(0.16-1.58)$ & 0.24 \\
\hline Preoperative PSA & $1.04(0.95-1.13)$ & 0.46 & $1.04(0.93-1.17)$ & 0.46 \\
\hline Extent of cancer on biopsy & $1.24(1.09-1.41)$ & $<0.01$ & $1.22(1.05-1.42)$ & 0.01 \\
\hline Gleason score on biopsy & $2.82(1.27-6.26)$ & 0.01 & $2.43(1.01-5.85)$ & 0.05 \\
\hline PNI on biopsy & $1.52(0.38-5.97)$ & 0.55 & $1.23(0.28-5.29)$ & 0.78 \\
\hline
\end{tabular}

$C I=$ confidence interval $; P N I=$ perineural invasion.

$>\mathrm{T} 2$ on radical prostatectomies. In patients with less extensive tumors on biopsy $(\leq 13.6 \%$ of tissue in $\mathrm{mm}$ containing carcinoma) and PNI, there was no association to any one clinical or pathological variable studied; no difference in the time to biochemical (PSA) progression-free outcome compared to patients without PNI; and, no predictive value for pathological stage $>$ pT 2 on both univariate and multivariate analysis. The only study to mention the influence of extent of tumor to the predictive value of PNI is Rubins's et al. (6). In their study, PNI revealed a significant association with stage pT3 on univariate analysis. However, on multivariate analysis the association was significant only when the greatest percentage of any single biopsy involved by prostate carcinoma and the total percentage of cancer in all cores were not considered, due to a significant interaction between these measures and PNI. 
Table 4 - Univariate and multivariate logistic regression analyses of several clinical and pathological variables predictive of pathological stage $>$ pT2 (pT3a/pT3b) on 132 biopsies with more extensive tumors (> 13.6\% of tissue in mm containing carcinoma).

\begin{tabular}{lcccc}
\hline $\begin{array}{c}\text { Clinical and Pathological } \\
\text { Variables }\end{array}$ & $\begin{array}{c}\text { Univariate Analysis } \\
\text { Hazard ratio } \\
\mathbf{( 9 5 \% ~ C I )}\end{array}$ & p Value & $\begin{array}{c}\text { Multivariate Analysis } \\
\text { Hazard ratio } \\
\mathbf{( 9 5 \% ~ C I ) ~}\end{array}$ & p Value \\
\hline Age & $1.02(0.97-1.08)$ & 0.41 & $1.01(0.94-1.07)$ & 1.00 \\
Clinical stage & $1.48(0.68-3.20)$ & 0.32 & $0.88(0.36-2.20)$ & 0.79 \\
Preoperative PSA & $1.09(1.03-1.15)$ & 0.01 & $1.07(1.00-1.08)$ & 0.06 \\
Extent of cancer on biopsy & $1.06(1.03-1.08)$ & $<0.01$ & $1.05(1.03-1.08)$ & $<0.01$ \\
Gleason score on biopsy & $1.92(1.13-3.30)$ & 0.02 & $1.47(0.79-2.73)$ & 0.22 \\
PNI on biopsy & $3.32(1.48-3.33)$ & $<0.01$ & $1.67(0.64-4.37)$ & 0.30 \\
\hline
\end{tabular}

$C I=$ confidence interval; $P N I=$ perineural invasion.

The findings with more extensive tumors on biopsy are in accordance with most of the studies in the literature. Egan and Bostwick (2) found on univariate analysis that PNI on needle biopsy was significantly associated to extraprostatic extension and seminal vesicle invasion. On multivariate analysis, however, only preoperative PSA, proportion of the biopsy involved by cancer, and Gleason score were significant. Ukimura et al. (4) found that PNI on biopsy was a good predictor among others studied for extraprostatic extension on univariate analysis but not on multivariate analysis. In the study by Vargas et al. (5) PNI was not an independent predictor of extraprostatic extension when PSA was included.

D'Amico et al. (7) evaluated the clinical use of PNI on biopsy for predicting time to PSA failure following radical prostatectomy of 750 men with clinically localized or PSA detected prostate cancer. The presence of PNI on biopsy was not a significant predictor of PSA outcome following RP for patients in the intermediate or high-risk group. O'Malley et al. (9) compared 78 biopsies with PNI with 78 matched controls without PNI and were unable to show that PNI on needle biopsy influences long-term tumor-free survival. Freedland et al. (10) studied 190 men who underwent radical prostatectomy. Percent of tissue with cancer on biopsy was the strongest predictor of biochemical recurrence on multivariate analysis. PNI was not an independent predictor of either adverse pathology or biochemical failure.

In Bismar's et al. study (11) neither presence nor absence of perineural nor number nor percentage of positive nerves were related to pathologic stage on univariate or multivariate analyses. In Tsuzuki's et al. study (12) PSA, Gleason score, digital rectal examination, percent of side specific cores with tumor and average percent involvement of each positive core but not PNI were found to be statistically significant independent predictors of extraprostatic extension in the region of the neurovascular bundle. Studying 452 consecutive patients undergoing radical retropubic prostatectomy by a single surgeon, Cannon et al. (13) concluded that although biopsy PNI alone was associated with a higher probability of extraprostatic extension, it was not predictive of bilateral nervesparing technique or a positive surgical margin in an individual patient.

In other studies, however, PNI was an independent predictor of final pathologic stage. de la Taille et al. (3) found that PNI, PSA and Gleason score on the biopsy independently predicted stage pT3 disease. The authors concluded that PNI is an important preoperative predictor of pathologic stage and should be reported when adenocarcinoma is diagnosed on prostate needle biopsies. In the Sebo et al. study (8) joint predictors of extraprostatic exten- 
sion were the percent cores positive for carcinoma, Gleason score of 7, Gleason score of 8 or 9 , serum PSA and PNI. In the Loeb et al. study (15), PNI was significantly associated with aggressive pathology and biochemical progression. On multivariate analysis, PNI was significantly associated with extraprostatic extension and seminal vesicle invasion. Bastacky et al. (1) studied 302 needle prostatic biopsies and found a sensitivity of $27 \%$ and a specificity of $96 \%$ for PNI to predict extraprostatic extension. They concluded that measuring PNI on needle biopsy helps identify extraprostatic extension and may help in planning nerve-sparing radical prostatectomy in the decision of whether to sacrifice part or all of the neurovascular bundle on the side of the biopsy. These authors did not study the predictive value on multivariate analysis.

Some factors may be responsible for the discrepancies in the literature: the number of cores examined per case may influence the rate of detection of PNI, the different methods of processing and submitting tissue from radical prostatectomy specimens (completely vs. partially embedded prostate glands) may contribute to different rates of detection of extraprostatic carcinoma, different definitions of PNI on needle biopsy tissue and extraprostatic extension, and different values of PSA for evaluation of biochemical progression-free outcome following surgery. In a search from January 1990 to December 2005 using MEDLINE, Embase, and the Web of Knowledge, Harnden et al. (14) performed a systematic review of studies that examined the association between perineural invasion and prostate cancer recurrence. These authors concluded that a considerable variation in study design, execution, and reporting precluded meta-analysis and quantitative risk estimation.

The frequency of perineural invasion on needle prostatic biopsies varies from $11 \%$ to $38 \%$ (1$6,8,10,11)$. Considering all biopsies in our study the frequency was $18 \%$. In the group with less extensive tumors the frequency was $10.6 \%$ and in the group with more extensive tumors $25.8 \%$. It is worth noting that in less extensive tumors the frequency of PNI is in the lower range of the frequency found in the literature. Studying very small tumors on biopsies (less than 1 $\mathrm{mm}$ in length in only one core), Thorson et al. (23) still found a frequency of $2 \%$ of PNI. We have also seen PNI invasion in autopsied patients with very small incidentally found histologic carcinomas. These findings probably suggest that PNI may be an early event. This suggestion is shared by Byar and Mostofi (24). The authors studied 208 total prostates removed using the step-section technique for early carcinoma of the prostate. The high frequency of PNI found (84.1\%) suggested by the authors that the phenomenon occurs early in the course of the disease. The similarity in the survival rates for cases with and without PNI indicated little if any prognostic significance.

Our study may have some limitations. All patients were submitted to radical prostatectomy, and therefore we were unable to determine any different effect of PNI on biochemical progression-free outcome with other forms of treatment, such as watchful waiting or radiotherapy. Another limitation could be related to the fact that we only recorded the presence or absence of PNI on needle biopsy but did not quantify the extent. In addition, the mean follow-up is relatively short, and it is possible that greater differences could occur with additional follow-up. A strength of the study could be the homogeneity of the study population which was comprised of consecutive patients treated by one expert surgeon limiting any influence of variability in surgical technique and the pathological evaluation also by one senior uropathologist.

In summary, tumor extent on needle biopsies influences the predictive value of PNI for pathologic stage $>\mathrm{pT} 2$ (pT3a and/or pT3b) on radical prostatectomies. In patients with more extensive tumors on needle biopsy, PNI predicted pathologic stage $>$ pT2 on radical prostatectomy on univariate analysis but on multivariate analysis did not show independent predictive value. This finding is in accordance to most of the studies reported in the literature. In patients with less extensive tumors on biopsy ( $\leq$ $13.6 \%$ of tissue in mm containing carcinoma) and PNI, there was no association between any clinical or pathological variables studied; no difference in the time to biochemical (PSA) progression-free outcome comparing to patients without PNI; and, no predictive value for pathological stage $>$ pT2 on both univariate and multivariate analysis. With a higher number of small tumors currently detected, there is no evidence that perineural invasion should influence the decision on preservation of the nerve during radical prostatectomy. 


\section{CONFLICT OF INTEREST}

\author{
None declared.
}

\section{REFERENCES}

1. Bastacky SI, Walsh PC, Epstein JI: Relationship between perineural tumor invasion on needle biopsy and radical prostatectomy capsular penetration in clinical stage B adenocarcinoma of the prostate. Am J Surg Pathol. 1993; 17: 336-41.

2. Egan AJ, Bostwick DG: Prediction of extraprostatic extension of prostate cancer based on needle biopsy findings: perineural invasion lacks significance on multivariate analysis. Am J Surg Pathol. 1997; 21: 1496-500.

3. de la Taille A, Katz A, Bagiella E, Olsson CA, O’Toole $\mathrm{KM}$, Rubin MA: Perineural invasion on prostate needle biopsy: an independent predictor of final pathologic stage. Urology. 1999; 54: 1039-43.

4. Ukimura O, Troncoso P, Ramirez EI, Babaian RJ: Prostate cancer staging: correlation between ultrasound determined tumor contact length and pathologically confirmed extraprostatic extension. J Urol. 1998; 159: 1251-9.

5. Vargas SO, Jiroutek M, Welch WR, Nucci MR, D'Amico AV, Renshaw AA: Perineural invasion in prostate needle biopsy specimens. Correlation with extraprostatic extension at resection. Am J Clin Pathol. 1999; 111: 223-8.

6. Rubin MA, Bassily N, Sanda M, Montie J, Strawderman MS, Wojno K: Relationship and significance of greatest percentage of tumor and perineural invasion on needle biopsy in prostatic adenocarcinoma. Am J Surg Pathol. 2000; 24: 183-9.

7. D'Amico AV, Wu Y, Chen MH, Nash M, Renshaw AA, Richie JP: Perineural invasion as a predictor of biochemical outcome following radical prostatectomy for select men with clinically localized prostate cancer. J Urol. 2001; 165: 126-9.

8. Sebo TJ, Cheville JC, Riehle DL, Lohse CM, Pankratz VS, Myers RP, et al.: Predicting prostate carcinoma volume and stage at radical prostatectomy by assessing needle biopsy specimens for percent surface area and cores positive for carcinoma, perineural invasion, Gleason score, DNA ploidy and proliferation, and preoperative serum prostate specific antigen: a report of 454 cases. Cancer. 2001; 91: 2196-204.
9. O'Malley KJ, Pound CR, Walsh PC, Epstein JI, Partin AW: Influence of biopsy perineural invasion on longterm biochemical disease-free survival after radical prostatectomy. Urology. 2002; 59: 85-90.

10. Freedland SJ, Csathy GS, Dorey F, Aronson WJ: Percent prostate needle biopsy tissue with cancer is more predictive of biochemical failure or adverse pathology after radical prostatectomy than prostate specific antigen or Gleason score. J Urol. 2002; 167: 516-20.

11. Bismar TA, Lewis JS Jr, Vollmer RT, Humphrey PA: Multiple measures of carcinoma extent versus perineural invasion in prostate needle biopsy tissue in prediction of pathologic stage in a screening population. Am J Surg Pathol. 2003; 27: 432-40.

12. Tsuzuki T, Hernandez DJ, Aydin H, Trock B, Walsh PC, Epstein JI: Prediction of extraprostatic extension in the neurovascular bundle based on prostate needle biopsy pathology, serum prostate specific antigen and digital rectal examination. J Urol. 2005; 173: 450-3.

13. Cannon GM Jr, Pound CR, Landsittel DP, Bastacky SI, Dhir R, Becich MJ, et al.: Perineural invasion in prostate cancer biopsies is not associated with higher rates of positive surgical margins. Prostate. 2005; 63: 336-40.

14. Harnden P, Shelley MD, Clements H, Coles B, Tyndale-Biscoe RS, Naylor B, et al.: The prognostic significance of perineural invasion in prostatic cancer biopsies: a systematic review. Cancer. 2007; 109: 1324.

15. Loeb S, Epstein JI, Humphreys EB, Walsh PC: Does perineural invasion on prostate biopsy predict adverse prostatectomy outcomes? BJU Int. 2009; 19. [Epub ahead of print]

16. Bostwick DG, Montironi R: Evaluating radical prostatectomy specimens: therapeutic and prognostic importance. Virchows Arch. 1997; 430: 1-16.

17. Epstein JI, Carmichael M, Walsh PC: Adenocarcinoma of the prostate invading the seminal vesicle: definition and relation of tumor volume, grade and margins of resection to prognosis. J Urol. 1993; 149: 1040-5.

18. Billis A, Freitas LL, Magna LA, Samara AB, Ferreira $\mathrm{U}$ : Prostate cancer with bladder neck involvement: pathologic findings with application of a new practical method for tumor extent evaluation and recurrencefree survival after radical prostatectomy. Int Urol Nephrol. 2004; 36: 363-8.

19. Billis A, Magna LA, Ferreira U: Correlation between tumor extent in radical prostatectomies and preoperative PSA, histological grade, surgical margins, and extraprostatic extension: application of a new practical 
method for tumor extent evaluation. Int Braz J Urol. 2003; 29: 113-9; discussion 120.

20. Gleason DF, Mellinger GT: Prediction of prognosis for prostatic adenocarcinoma by combined histological grading and clinical staging. J Urol. 1974; 111: 5864.

21. Gleason DF: Histologic grading and clinical staging of prostatic carcinoma. In: Tannenbaum M (ed.), Urologic pathology: The prostate. Philadelphia, Lea \& Febiger. 1977; pp. 171-98.

22. Cookson MS, Aus G, Burnett AL, Canby-Hagino ED, D'Amico AV, Dmochowski RR, et al.: Variation in the definition of biochemical recurrence in patients treated for localized prostate cancer: the American Urological Association Prostate Guidelines for Localized Prostate Cancer Update Panel report and recommendations for a standard in the reporting of surgical outcomes. J Urol. 2007; 177: 540-5.

23. Thorson P, Vollmer RT, Arcangeli C, Keetch DW, Humphrey PA: Minimal carcinoma in prostate needle biopsy specimens: diagnostic features and radical prostatectomy follow-up. Mod Pathol. 1998; 11: 543-51.

24. Byar DP, Mostofi FK: Carcinoma of the prostate: prognostic evaluation of certain pathologic features in 208 radical prostatectomies. Examined by the step-section technique. Cancer. 1972; 30: 5-13.

\section{Correspondence address:}

Dr. Athanase Billis

Anatomia Patológica, FCM, Unicamp

Caixa Postal 6111

Campinas, SP, 13084-971, Brazil

E-mail: athanase@fcm.unicamp.br 


\section{EDITORIAL COMMENT}

The importance of perineural invasion (PNI) in prostate biopsies remains controversial in the literature. The studies published since 1993 have shown an incidence of PNI variable from $11 \%$ to $38 \%$ significantly related to unfavorable histological features, specially extra-prostatic extension (EPE) and positive surgical margins $(1,2)$. Some authors have shown a relationship between PNI and biochemical recurrence, and because of that, the description of the presence or absence of PNI in prostate biopsies plays a role in surgical pathology reports. The authors studied 264 patients, finding $18.2 \%$ of PNI related to EPE, higher Gleason score and seminal vesicles (SV) infiltration only for extensive tumors. However, they did not find any correlation between PNI and tumor progression. The most robust study was published recently by Loeb et al. (3) describing the Johns Hopkins experience with 1256 men submitted to radical prostatectomy, and they found a correlation between PNI with EPE and SV infiltration in multivariate analysis. In addition to the fact that tumor progression occurred in $10.5 \%$ of patients with PNI and in only $3.5 \%$ of patients without PNI, this aspect was not an independent risk factor for biochemical

\section{EDITORIAL COMMENT}

The authors are to be commended on this thorough analysis of how transrectal prostate needle biopsy specimens correlate with whole mount prostatectomy specimens. This study is solid based on the large number of patients (264). There is further strength in that a single surgeon performed each radi- recurrence. Most importantly, it was not considered to decide nerve-sparing surgery. Since there is some agreement that PNI is related to aggressive pathologic features, we believe it is important that pathologists continue to describe the presence or absence of PNI to give the opportunity to surgeons, oncologists and radiotherapists to take this aspect in account to better plan patients' treatment.

\section{REFERENCES}

1. Rubin MA, Bassily N, Sanda M, Montie J, Strawderman MS, Wojno K: Relationship and significance of greatest percentage of tumor and perineural invasion on needle biopsy in prostatic adenocarcinoma. Am J Surg Pathol. 2000; 24: 183-9.

2. Bismar TA, Lewis JS Jr, Vollmer RT, Humphrey PA: Multiple measures of carcinoma extent versus perineural invasion in prostate needle biopsy tissue in prediction of pathologic stage in a screening population. Am J Surg Pathol. 2003; 27: 432-40.

3. Loeb S, Epstein JI, Humphreys EB, Walsh PC: Does perineural invasion on prostate biopsy predict adverse prostatectomy outcomes? BJU Int. 2009 Aug 19. [Epub ahead of print].

Dr. Katia Ramos Moreira Leite Laboratory of Medical Investigation Divisio of Urology, School of Medicine University of Sao Paulo, USP São Paulo, SP, Brazil E-mail: katiaramos@uol.com.br

cal retropubic prostatectomy, while all of the pathology was interpreted by a single pathologist. Finally, the statistical methods employed were appropriate for this type of analysis.

In the literature, there is great controversy regarding the significance of perineural invasion 
(PNI). There are as many reports to suggest significance of PNI as there are reports that demonstrate no difference in patient outcomes. Specifically, can PNI predict preoperatively the presence of extracapsular extension (ECE) at the time of radical prostatectomy? Naturally, if this can be shown that a patient is at risk preoperatively for ECE, the surgeon may electively alter the technique to sacrifice part or all of the neurovascular bundle on the ipsilateral side of the disease. Additionally, this information may be useful in counseling patients pre-treatment regarding the pros and cons of various treatment options.

This report by Billis et al., does in fact demonstrate a subset of patients that have a significant risk of having a higher grade Gleason score, ECE and seminal vesicle involvement at the time of radical prostatectomy. Specifically, it was the group of patients in that more than $13.6 \%$ of linear $(\mathrm{mm})$ malignant involvement was identified in the needle biopsy specimens. $25.8 \%$ of this cohort possessed PNI. Fortunately, regarding overall freedom from biochemical progression, there was no significant difference between those with and without PNI. Without question, better pretreatment patient selection will ultimately improve treatment outcomes. It is not uncommon to assume a patient has low risk criteria when in fact, they may harbor more advanced disease. In the future, clinicians will utilize more sophisticated biopsy techniques and apply known pathologic risk factors to decrease the risk of understaging prostate cancer.

Dr. Brian J. Moran Medical Director, Radiation Oncology Chicago Prostate Center Westmont, Illinois, USA E-mail:seeds@prostateimplant.com 